research

\title{
Impacting attitudes towards gambling: A prison gambling awareness and prevention program
}

Gary Nixon, University of Lethbridge, Lethbridge, Alberta, Canada.

E-mail: gary.nixon@uleth.ca

Gordon Leigh, Lethbridge John Howard Society, Lethbridge, Alberta, Canada.

Nadine Nowatzki, University of Manitoba, Winnipeg, Manitoba, Canada.

\begin{abstract}
Research indicates that approximately one third of prison inmates meet the criteria for problem or pathological gambling (Williams, Royston, \& Hagen, 2005). However, despite this rate being among the highest of all gambling populations (Walters, 1997; Shaffer \& Hall, 2001), there appears to be a lack of prison gambling awareness and prevention programs. This study sought to develop, implement, and evaluate one such program at the Lethbridge Correctional Facility in Alberta, Canada. Forty-nine inmates completed a six-session program over 18 months. Gambling screen results revealed a significant increase in cognitive error recognition, and attitudes towards gambling became significantly more negative. The program did not render any significant differences in math skill score, Canadian Problem Gambling Index (CPGI) score, or past-year South Oaks Gambling Screen (SOGS) score. Changes in the past-year frequency score approached significance. This study suggests that programs of this kind can be effective for inmate populations, particularly in changing attitudes towards gambling.
\end{abstract}

Key words: prison, inmate, problem gambling, pathological gambling, prevention

\section{Introduction}

The purpose of the Gambling Awareness and Prevention Project was to develop, implement, and evaluate a psycho-educational gambling program for prison inmates that focused on awareness of gambling and problem gambling, cognitive distortions (reduction of thinking errors), and attitudes towards gambling (towards a more realistic and negative perspective). The program was delivered from 2002 to 2004 through collaboration between the Lethbridge John Howard Society, a prominent prisoner rehabilitation agency that delivers addiction recovery programs inside prisons, and the Addictions Counselling Faculty of the School of Health Sciences at the University of Lethbridge.

During the past two decades, there has been increased acceptance of gambling in areas where legalized gambling has been introduced (Shaffer, Hall, \& Vander Bilt, 1997). As the availability of gambling venues in North America has increased, legalized gambling has become a commonplace cultural pastime (Cox, Lesieur, Rosenthal, \& Volberg, 1997; Hope \& Havir, 2000; Morgan Research, 1997; Volberg, 2002; Williams et al., 2005). In the mid-1990s in southern Alberta, the local executive director of the John Howard Society began noticing an increase in the number of inmates convicted of gambling-related offences, mainly 
economic crimes, in the local correctional centre. This increase appeared to correspond to the introduction of video lottery terminals (VLTs) in pubs, lounges, and bars beginning in 1992 in Alberta and to the opening of casinos in 1996.

However, there was no indication that gambling awareness and prevention programs existed in prisons in Alberta, or even in Canada. Problem gamblers were showing up in recovery programs intended for alcohol and drug abusers. This observation became the impetus behind the creation of the Gambling Awareness and Prevention Project in 2002.

\section{International trends in problem gambling among prison inmates}

Previous studies have reported prison prevalence rates ranging from $12 \%$ to $38 \%$, depending on the instruments and criteria used and the population sampled (Abbot \& McKenna, 2000; Abbot, McKenna, \& Giles, 2000; Anderson, 1999; Kerber, 2000; Lesieur \& Klein, 1985; Maden, Swinton, \& Gunn, 1992; Templer, Kaiser, \& Siscoe, 1993; Walters, 1997). Williams et al. (2005) reviewed 28 prevalence studies conducted among prison populations in countries such as Australia, New Zealand, the UK, and the US and found a combined problem and pathological gambling prevalence rate of almost 33\%. Williams et al. (2005) and Crockford and el-Guebaly (1998) suggested that the high rates of problem and pathological gambling in prison populations are traceable to offender demographic characteristics (young, male, minority group status) and comorbidities (substance abuse, antisocial personality). However, research points to the fact that gambling is a significant problem with female inmates as well. Abbott and McKenna (2000) report a 33\% lifetime pathological gambling rate and a further 12\% problem gambling rate in their study of 94 recently sentenced female prison inmates.

In addition, Abbott and McKenna (2000) and Bellringer (1986) have found that a significant amount of gambling takes place within prisons despite the fact that gambling in prison is banned in the various jurisdictions. In New Zealand, $28 \%$ of recently imprisoned women and $26 \%$ of men reported gambling participation, the majority of whom gambled weekly or more often (Abbott \& McKenna, 2000; Abbot et al., 2000).

Previous studies have concluded that addictive gambling behaviour is an important criminogenic factor, with $77 \%$ to $89 \%$ of surveyed pathological gamblers admitting to having committed a criminal offence (Brown, 1987; Meyer \& Stadler, 1999). Most crimes are nonviolent (i.e., income generating or property related) including fraud, forgery, embezzlement, larceny, selling drugs or stolen goods, shoplifting, burglary, and petty theft or robbery (Abbott \& McKenna, 2000; Brown, 1987; Lesieur \& Puig, 1987; Meyer \& Stadler, 1999). The majority of crimes committed appear to be gambling related in that they are committed to finance gambling activities or pay gambling-produced debts, and a significant proportion of problem gamblers indicate that they have been arrested or convicted for a gambling-related offence (Abbott \& McKenna, 2000; Blaszczynski, McConaghy, \& Frankova, 1991; Lesieur \& Klein, 1985; Potenza et al., 2000).

To date, a study of the prevalence of problem gamblers among Canada's prison populations has not been concluded. However, a subculture of gambling in prisons has been noted anecdotally. Gambling may occur as a pastime to alleviate boredom, despite its prohibition within the prison. However, gambling among prisoners may be difficult to detect by prison staff. The justification for a gambling prevention and education program is based on two 
interconnected issues: (a) high problem gambling prevalence rates in prison populations where research has been conducted and (b) the link between problem gambling and criminal behaviour.

While further substantiating the relationship between crime and gambling is beyond the scope of this study, it can be reasonably assumed that a prevention program that improved prisoners' attitudes and potentially their gambling behaviours might diminish criminal activity. Prison substance abuse programs have shown their rehabilitation potential, with therapeutic community programs enjoying particular success with a $23 \%$ rate of return to prison or violation of parole 3 years after release (Levinthal, 1999). However, the lack of research into prison gambling programs makes this link difficult to assess. Lahn and Grabosky (2003) warn that it is seductive to purport a link between problem gambling and crime, as not all problem gamblers offend and some offend for reasons unrelated to gambling.

\section{Prison gambling programs and crime prevention}

The treatment of pathological gambling behaviour is believed to be an effective strategy to reduce or prevent the risk of further criminal behaviour, particularly in cases where gambling addiction has led to property crimes (Meyer \& Stadler, 1999). Brown (1987) found that once gambling behaviour is changed there are rarely any further convictions. Yet with regard to interventions for problem gambling, offenders are an underserved population. Anderson (1999) has suggested that further assessment of gambling problems among incarcerated offenders is needed and recommends the inclusion of gambling topics in treatment and release programs. Walters (1997) points out that "intervention needs to be made available to these individuals, but it must be made relevant to the problems and concerns of gamblinginvolved incarcerated offenders" (p. 22).

Unfortunately, there appear to be relatively few published accounts of prison gambling prevention programs internationally. Lahn and Grabosky (2003) reviewed various methods for offender screening and treatment specifically in relation to problem gambling in Australia. They found that all states assess offenders for risk and need, but no assessment tools are used explicitly for gambling. Although all states have offender programs, only two (New South Wales and Victoria) have a specific program for gambling problems. In the UK, gambling has not been a focus of correctional services, but Gamblers Anonymous runs groups for people with gambling problems in some prisons. Currently, a few US states (e.g., New York, Minnesota, Nevada) have specific gambling programs for incarcerated prisoners (Williams et al., 2005; Lahn \& Grabosky, 2003). In Canada, the gambling awareness program piloted at the Lethbridge Correctional Centre, which is the focus of this study, appears to be the only prison gambling program operating at this time (Lahn \& Grabosky, 2003; Williams et al., 2005).

To summarize, the high problem-pathological gambling rate in prisons, the existence of a gambling subculture among inmates, the link between gambling and crime, and the lack of gambling programs in Canadian prisons all point to the importance of developing a gambling educational awareness and prevention program for prison populations in Canada and elsewhere. 


\section{A prison gambling awareness and prevention program}

\section{Description}

The goals of the Gambling Awareness and Prevention Project were to develop and implement a program that would educate prison populations and to measure the degree, if any, of that program's impact on participants' attitudes, knowledge, and behaviour. The Gambling Awareness and Prevention Project comprised a series of six 90-minute group sessions offered to men and women inmates serving their sentences at the Lethbridge Correctional Centre in southern Alberta. The series was delivered on six separate occasions over a 15-month period (2002-2004) at the Centre. Inmates registered voluntarily for the program. Participants were surveyed at the beginning and end of each series using a combination of problem gambling instruments to measure any changes in their awareness of problem gambling, attitudes towards gambling, odds (math) calculation skills, cognitive skills, and behaviour.

\section{Design}

The gambling program fell into the evening "support" programming at the Lethbridge Correctional Centre. Other programs, such as academic upgrading programs and skill training, were scheduled during the daytime. Support programs deal largely with life skills subjects and were allowed a limited time slot and had to share evening time slots with other support programs. On that basis, a time slot of one and a half hours was selected for the gambling program.

A further consideration was the optimum length of time during which a serving prisoner could attend a complete series of program components. Inmates of provincial correctional centres such as the Lethbridge Correctional Centre serve shorter sentences than prisoners in penitentiaries. The average time is less than 3 months when the statutory remission of one third of the sentence is taken into account. Exacerbating the limited time frame were factors such as frequent transfer of inmates to other correctional centres, transfers for appeals, and disciplinary procedures that can interrupt continuous attendance at programs. A further disruption during the program time was caused by extensive kitchen renovations, which led to a reduction of the inmate population and a high number of transfers to other centres in the province. Originally, the gambling program was scheduled for one session per week over 6 weeks, but for the reasons mentioned above it was changed to occur twice a week over a 3week period to maximize uninterrupted enrolment.

Consequently, it was necessary to select six topics that would adequately cover the core content of a gambling awareness and prevention program that would provide cohesion and integrity within the goals of the program. This was done through consultation with addiction experts at the University of Lethbridge and by exploring other successful addictions programs delivered previously at the Centre as well as reviewing gambling literature on such topics as cognitive distortions and the phases of gambling (Andres \& Hawkeye, 1997; Toneatto, Blitz-Miller, Calderwood, Dragonetti, \& Tasanos, 1997). The overall direction of the program was to move from awareness to wellness through the six-part series. The program consisted of the following topics: 
1. definitions of addiction and gambling addiction, types of gambling, and facts about problem gambling;

2. phases and progression of problem gambling and the negative consequences of problem gambling;

3. external reinforcement of addiction and problem gambling through an outside speaker (two guest speakers from Gamblers Anonymous) or appropriate video, Gambling: It's Not About Money (Hazelden Foundation, 2000), followed by discussion of key points;

4. the reality of odds and characteristics of denial and cognitive distortions and false beliefs, called "mistaken thinking" in the program, and the realities behind such thinking, sometimes referred to as "myth-busting";

5. identifying barriers to quitting problem gambling and ways of overcoming barriers, relapse triggers, and the development of a relapse prevention plan, including techniques for selfprotection;

6. alternatives to gambling and the development of a lifestyle plan, a reminder of signs of problem gambling, and follow-up services for problem gamblers.

Each session of the program was designed as a free-standing unit of information without dependence on the other units in the series. Thus, individual sessions were intended to produce a singular contribution to the overall impact of the program. In this way, the program borrowed from brief counselling theory, in which each counselling session is considered as potentially the only session during which to facilitate some degree of change in the individual (Cade \& O'Hanlon, 1993). While the structure of free-standing units was retained in designing and delivering the Gambling Awareness and Prevention Project, entry into the program at any point in the series was not allowed in order to maintain consistency between pre- and posttesting of inmates attending the program. As a result of this decision, there was an average attrition rate of one third in each series due to transfers out, disciplinary measures, and voluntary withdrawal.

\section{Procedure}

Recruitment for the program was voluntary and was accomplished by placing a notice in each living unit of the Centre giving details of the program and the start date, along with the sign-up process. This was the same process for requesting a service, namely filling out an inmate request form to be placed on the program list. There was no prescreening involved in determining who might participate in the program, since the program was preventive as well as awareness providing, and no exclusion criteria applied. Once the list of participants was known, the first set of evaluative screens and instruments was administered before the program began.

Participants were issued a workbook organized into six sections that included subtopics for each session. Each session of the program was highly interactive and Socratic in method, whereby the group leader asked questions to elicit answers from participants, who responded with information drawn from their cumulative knowledge and experience. When information was not forthcoming, the facilitator provided it to the group. Each component of 
the session was examined thoroughly; for instance, in the first session, definitions of gambling, problem gambling, "betting," and addiction were explored. As well, various types of gambling that require skill or no skill were listed and compared to statistics on the most popular types of gambling.

Following discussion and answers, which were written on the chalkboard, the group members wrote down the information in the relevant section of their workbook. Individual group members could tailor the information and its emphasis to their own particular experiences, circumstances, needs, and plans. This process was intended to give group members a sense of ownership in developing answers and solutions to the issues addressed in the program and provide them with a personal record of the information in their workbook.

Of necessity, the group facilitator was knowledgeable about the topics and experienced in using group interaction techniques to guide participants through the program content. In addition, the workbook contained factual and technical information about gambling that group members most likely would not know, for instance, a profile of gambling expenditures of problem gamblers and an explanation of the progressive nature of gambling addiction. This information was necessary and added to the knowledge and experience contributed by the group and ultimately their awareness of problem gambling and its consequences and prevention.

Communication, both spoken and written, was at the grade 8 to 10 level so as to be understandable by all participants. Many prison inmates are familiar with terms associated with various addictions, both from their own culture and conversations and from prior involvement in addictions counselling. Nonetheless, technical terms were replaced with more familiar terms where possible to aid understanding and to avoid distancing the facilitator from the group through language. For instance, the term "cognitive distortion" would be replaced by wording such as "mistaken thinking."

At the end of the program, a Certificate of Completion was awarded to each participant who finished all six sessions of the program. For those who were unable to complete the program through no fault of their own (for example, through being transferred, court appearances out of the region, sickness, or other similar reasons) a Certificate of Attendance was provided prior to leaving the group in recognition of their participation in the program.

\section{Instruments}

The South Oaks Gambling Screen (SOGS) for lifetime and past year was used for pre- and postprogram testing (Lesieur \& Blume, 1987, 1993). Scores of 3 or 4 are considered to indicate the presence of "problem gambling" and scores of 5 or higher "probable pathological gambling." The more recently developed Canadian Problem Gambling Index (CPGI) was also used. It has been tested as a reliable and valid instrument and uses a 12-month time frame (Ferris \& Wynne, 2001). It has four levels: non-problem gambling, low-risk gambling, moderate-risk gambling (roughly equivalent to "problem gambling"), and severe problem gambling (roughly equivalent to "pathological gambling"). These screens provided a baseline measure of the prevalence of problem gambling among the participants.

In conjunction with the gambling screens, a previously designed gambling questionnaire was also utilized that collects and assesses demographic information, cognitive errors in 
gambling (six questions), attitudes towards gambling (three questions), and the ability to calculate gambling odds (one question) (Connolly, Williams, \& Morris, 2001). The same screens and questionnaire were administered at the end of the program and completion was required in order for the inmates to receive a Certificate of Completion.

\section{Results}

Quantitative analysis using SPSS software was conducted to compile descriptive, demographic data and determine the effects of the awareness program. Paired $t$ tests were conducted to test for changes in attitudes, cognitive errors, odds calculation, gambling frequency past year, CPGI, and SOGS past year. It was deemed unnecessary to test for changes in SOGS lifetime scores due to the short duration of the program.

\section{Baseline sample}

A total of 71 inmates completed the baseline questionnaires. There were 46 males (64.8\%) and 25 females $(35.2 \%)$. The ages $(n=69)$ ranged from 18 to 58 , with an average age of 30 years. Of the 64 participants who included ancestry, $37(57.8 \%)$ were of European descent, 22 (34.4\%) Aboriginal, 3 (4.7\%) African, and 1 (1.6\%) each Hispanic and Asian. With regard to level of education $(n=65), 41(63.1 \%)$ had not completed grade 12, $21(32.3 \%)$ had a high school diploma, and only $3(4.6 \%)$ had some college or university. According to the CPGI at baseline, there were 9 (12.7\%) non-problem gamblers, 11 (15.5\%) low-risk gamblers, 27 (38\%) moderate-risk gamblers, and 24 (33.8\%) problem gamblers. According to the past-year SOGS $(n=71)$, there were $7(9.8 \%)$ problem gamblers and $33(46.5 \%)$ probable pathological gamblers. According to the lifetime SOGS $(n=64)$, there were 6 (9.4\%) problem gamblers and 34 (53.1\%) probable pathological gamblers.

\section{Follow-up sample}

Although 71 surveys were initially collected, only matched pretest/posttest pairs were included in the statistical analysis and 49 of the 71 individuals (69\%) completed follow-up questionnaires. Attrition occurred due to expected transfers in and out, loss of privileges and other disciplinary measures, short sentences, early releases, attendance at other compulsory activities, interruptions such as lockdowns and other institutional events, and voluntary withdrawal (e.g., more attractive entertainment options, such as sports on TV). There were 30 (61.2\%) males and 19 (38.8\%) females. Regarding age, 41 of 49 responded, with ages ranging from 18 to 53, and an average age of 30 years. Regarding ancestry, 46 participants responded, with 28 (57.8\%) being of European descent, 15 (30.6\%) Aboriginal, and 1 (2.0\%) each African, Hispanic, and Asian. With regard to level of education, 46 responded, where 29 (63\%) had not completed grade 12, 15 (32.6\%) had a high school diploma, and only $2(4.3 \%)$ had some university or college. According to the CPGI, with all 49 responding, there were 5 (10.2\%) non-problem gamblers, 8 (16.3\%) low-risk gamblers, 20 (40.8) moderate-risk gamblers, and 16 (32.7\%) problem gamblers. According to the pastyear SOGS $(n=49)$, there were $4(8.2 \%)$ problem gamblers and $23(46.9 \%)$ probable pathological gamblers. According to the lifetime SOGS $(n=47)$, there were $5(10.6 \%)$ problem gamblers and 23 (48.9\%) probable pathological gamblers. 


\section{Impact of the program}

Summary scores from each of the instruments were entered into SPSS 11.0 computer software (Paired samples $t$-test). A bar graph depicting the mean pre-test and post-test scores of each category visually represents the differences between the six categories (see Figure 1).

\section{Figure 1 Mean Pre- and Post-test Scores}

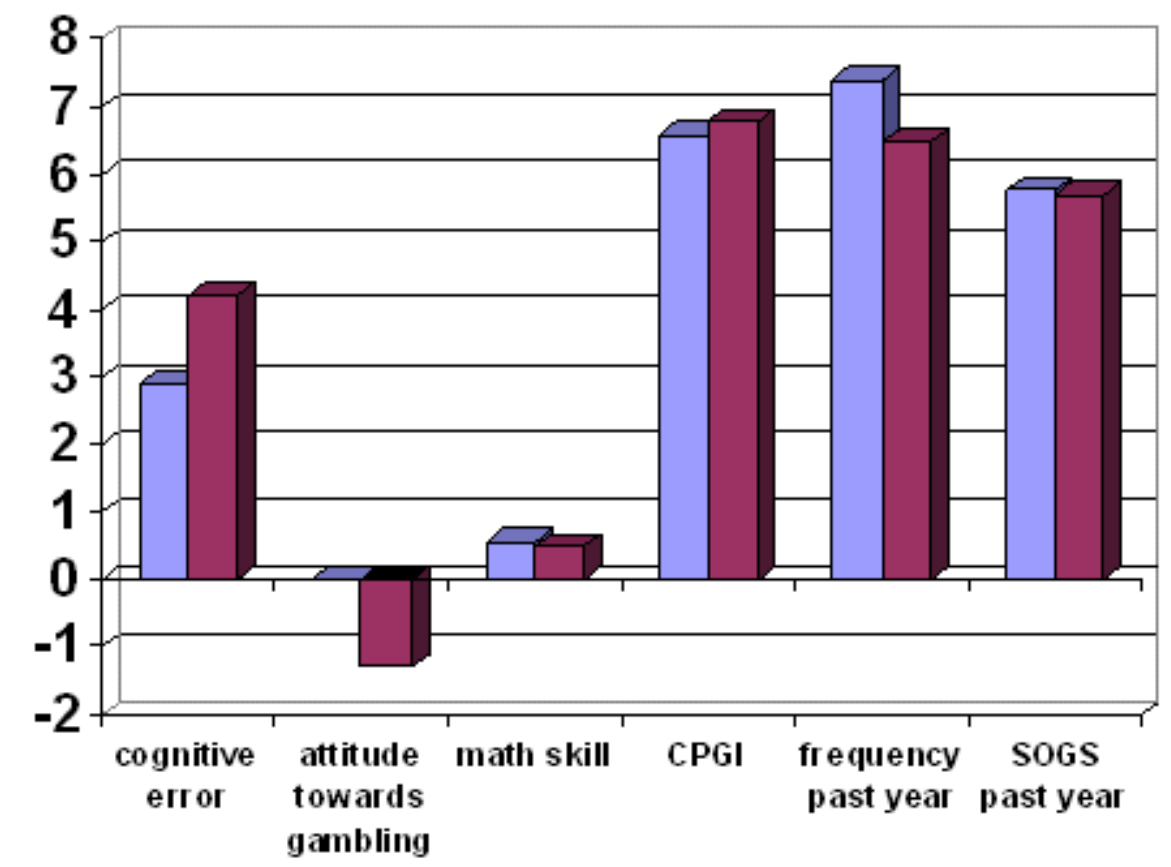

\section{$\square$ baseline $\square$ follow-up}

Means and standard deviations were calculated for each of the instruments (see Table 1), and pre-test scores were compared with post-test scores. With regard to the impact of the gambling awareness and prevention program, statistical analysis showed a significant

Table 1

\section{Paired samples results}

\begin{tabular}{lllll}
\hline Pair & Mean & $\mathrm{N}$ & $\begin{array}{l}\text { Std. } \\
\text { deviation }\end{array}$ & $\begin{array}{l}\text { Std. error } \\
\text { Mean }\end{array}$ \\
\hline Baseline cognitive error & 2.89 & 47 & 1.108 & .162 \\
Followup cognitive error & 4.21 & 47 & .931 & .136 \\
\hline Baseline attitude towards gambling & .00 & 49 & 3.069 & .438 \\
Followup attitude towards gambling & -1.29 & 49 & 2.389 & .341 \\
\hline Baseline math skill & .56 & 45 & .503 & .075 \\
Followup math skill & .49 & 45 & .506 & .075 \\
\hline Baseline CPGI & 6.59 & 49 & 5.712 & .816 \\
Followup CPGI & 6.78 & 49 & 6.734 & .962 \\
\hline Baseline past year freq & 7.39 & 49 & 4.769 & .681 \\
Followup past year freq & 6.49 & 49 & 4.874 & .696 \\
\hline Baseline past year SOGS & 5.76 & 49 & 5.914 & .845 \\
Followup past year SOGS & 5.69 & 49 & 6.329 & .904 \\
\hline
\end{tabular}

difference between the pre-test and post-test scores in two of the six pairs: cognitive errors $(p<0.001)$, and attitudes towards gambling $(p<0.01)$. Past year frequency of gambling 
approached significance $(p=0.087)$ (see Table 2).

\section{Table 2}

\section{Paired samples t-test comparing pre-program and post-program results}

\begin{tabular}{|c|c|c|c|c|c|c|c|c|}
\hline \multirow[b]{4}{*}{$\begin{array}{l}\text { Pair } 1 \\
\text { cognitive errors }\end{array}$} & \multirow{4}{*}{$\begin{array}{l}\text { Mean } \\
-1.32\end{array}$} & \multicolumn{2}{|c|}{ Paired differences } & & & \multirow[t]{3}{*}{$\mathrm{T}$} & \multirow[t]{3}{*}{$\mathrm{df}$} & \multirow{3}{*}{$\begin{array}{c}\text { Sig } \\
\text { (2-tailed) }\end{array}$} \\
\hline & & \multirow[t]{2}{*}{$\begin{array}{c}\text { Std. } \\
\text { deviation }\end{array}$} & \multirow[t]{2}{*}{$\begin{array}{c}\text { Std. } \\
\text { error } \\
\text { mean }\end{array}$} & \multicolumn{2}{|c|}{$\begin{array}{l}\text { 95\% confidence } \\
\text { interval of the } \\
\text { difference }\end{array}$} & & & \\
\hline & & & & Lower & Upper & & & \\
\hline & & 1.181 & .172 & -1.67 & -.97 & -7.65 & 46 & .000 \\
\hline $\begin{array}{l}\text { Pair } 2 \\
\text { attitude towards } \\
\text { gambling }\end{array}$ & 1.29 & 3.310 & .473 & .33 & 2.24 & 2.719 & 48 & .009 \\
\hline $\begin{array}{l}\text { Pair } 3 \\
\text { math skill }\end{array}$ & .07 & .539 & .080 & -.10 & .23 & .829 & 44 & .411 \\
\hline $\begin{array}{l}\text { Pair } 4 \\
\text { CPGI }\end{array}$ & -.18 & 4.522 & .646 & -1.48 & 1.12 & -.284 & 48 & .777 \\
\hline $\begin{array}{l}\text { Pair 5 } \\
\text { past year } \\
\text { frequency }\end{array}$ & .90 & 3.595 & .514 & -.13 & 1.93 & 1.748 & 48 & .087 \\
\hline $\begin{array}{l}\text { Pair } 6 \\
\text { past year SOGS }\end{array}$ & .06 & 4.455 & .636 & -1.22 & 1.34 & .096 & 48 & .924 \\
\hline
\end{tabular}

Correlation coefficients were calculated to determine if there were relationships between the variables. Not surprisingly, there was a significant correlation $(r=.287, p<0.05)$ between level of education and baseline math skill. There also was a significant correlation ( $r=-.238$, $\mathrm{p}<0.05)$ between age and baseline attitude towards gambling. Thus, as age increased, attitudes towards gambling became more negative. This is not surprising, as today's youth are the first to be raised in an environment with extensive legalized gambling and increased positive societal attitudes towards gambling.

\section{Discussion}

\section{Impact of program}

The purpose of the Gambling Awareness and Prevention Project was to develop a program that would educate prison populations and to measure the degree, if any, of that program's impact on attitudes, knowledge, and behaviour. It achieved this objective in terms of improving attitudes towards gambling and knowledge of cognitive distortions. Attitudinal shifts indicated that inmates no longer believed that gambling was a simple recreational pastime. Moreover, for many of the participants, this attitudinal shift included recognizing that they indeed had a problem with gambling and that gambling played a part in the mix of addiction and criminal activities that led them to become incarcerated. Through the recognition that gambling was part of a larger and ongoing "living problem," some inmates signalled their intention to enter counselling for their gambling addiction on release by making arrangements through their caseworker as part of their release plan. One individual even arranged to enter a treatment program upon leaving prison.

Most important, gambling was no longer viewed as an "innocent activity" but became 
recognized as an activity that held potential dangerous effects that are manifested when gambling becomes chronic in nature. If negative attitudes and cognitive error recognition play a part in behaviour change, the choice of entering this program may be a step in the right direction for those inmates who choose to commit themselves to responsible gaming participation and those who want to remain abstinent from gambling altogether. By improving gambling attitude, the program achieved an important step towards the final goal of improving gambling behaviour.

On the other hand, the program did not render any significant differences in math skill score, CPGI score, past-year frequency score, or past-year SOGS score. With regard to math (odds calculation) skill, only one question was used to measure this facet. Future studies could incorporate more math skill questions to increase reliability and the ability to detect a postprogram difference. As well, because odds calculation skills showed a reduction, not an improvement, more attention might be given in future to this area of programming.

Additionally, it is probably important to devote more attention to the cognitive distortions and mystique that surround the question of odds if a more realistic view of odds is to be gained.

We did not expect significant changes in past-year SOGS or CPGI scores, since program participants were incarcerated at the time of the program and therefore had limited opportunities to engage in forms of gambling normally available outside of prison. However, the data were collected in order to measure the prevalence of problem gambling among our participants at baseline, with the hopes that a future study would include follow-up data after release from prison. The lack of significant change in past-year gambling could also be due to the short duration of the program, and hence the minimal impact on past-year reporting. Future research could investigate the impact of a lengthier program, with a larger sample. However, due to the complexities of prison research, the delivery of a longer program may be difficult. More important, it is apparent that to measure the true impact of a prison awareness and prevention program, a follow-up at 6 months and 1 year after release from prison is needed. Despite positive shifts in attitudes and cognitive error recognition, this study was not able to determine whether or not offering an educational and awareness program focusing on problem/pathological gambling and its facets will help in reducing or eliminating problem gambling behaviour after inmates are released from prison, especially without ongoing individual or group support in the community.

It is also important to note that criminal records were not made available to the researchers, as that information was classified. Voluntary postprogram interviews with program participants pointed to such crimes as fraud, check forgery, break and enter, and drugrelated offences. Two participants engaged in bank robbery to secure money to gamble. Sex crime inmates were secluded from the general prison population and thus were not available for the program. The general nature of the crimes pointed towards nonviolent crimes against property and thus supported a link between gambling and crime, but without having access to all criminal records this link was impossible to systematically evaluate.

\section{Screening}

For the Gambling Awareness and Prevention Project, the issue of relevance of program to inmate need (Walters, 1987) is partly addressed by the fact that attendance at the program was voluntary. Inmates attended the program according to their perceived personal need. However, it is important to determine that there are other bases for a program than simply inmate choice, because some inmates may choose to attend for reasons of entertainment, to 
meet members of the opposite sex in the case of coeducational programs, or to see what the program is like in relation to other program choices. For these reasons, a prescreening instrument would be an effective tool in future programs to eliminate the merely curious.

Prescreening would also assist inmates to recognize the existence of their problematic gambling behaviour. As the program progressed, it became apparent that many of the participants were genuinely unaware of the severity of their problem gambling because they attributed all of their difficulties to an overwhelming single cause in their eyes, such as another addiction, typically substance abuse. Severe gambling disorders therefore can be "hidden" in some cases. In this circumstance, it can be expected that many inmates with gambling problems will be missed, if entering a program is purely on a voluntary basis. Assessment for gambling problems at the casework level, along with testing for substance abuse problems, would provide the information necessary for inmates to make an "informed" choice about entering a problem gambling program.

In setting up screening procedures for a gambling program, institutional factors must be kept in mind, as these factors will affect program numbers. Issues of attrition and late entry need to be considered in any similar prison gambling awareness and prevention research project and decisions made ahead about how these may affect the program and what course of action to take to ensure consistency and integrity.

\section{Prison gambling awareness and prevention programs}

At the time of providing this program, there were no known prison gambling programs in correctional facilities in Canada (Lahn \& Grabosky, 2003). The results of the program point to the need for further prison gambling programs with follow-up after the inmates leave prison to measure the impact of gambling programs not only on attitudes but also on gambling behaviour. As well, with the inroads achieved on affecting gambling attitudes, stronger links to follow-up addiction counselling services for inmates leaving prison would build on the momentum already established. In addition, further studies would track comorbidity, as many of the inmates spoke about other addictions in addition to gambling during the program, but no data were collected.

Overall, with the high prevalence rates of problem gambling within inmate populations identified in some studies, the link between gambling behaviour and crime, and the potential impact of a gambling program as seen here, it seems apparent that correctional institutions need to begin to implement gambling awareness and prevention programs as a regular part of prison programming. Further research is also needed into the characteristics and outcomes of a successful prison gambling awareness and prevention program.

\section{References}

Abbott, M., \& McKenna, B.G. (2000). Gambling and problem gambling among recently sentenced women prisoners in New Zealand. Wellington, New Zealand: The Department of Internal Affairs.

Abbott, M.W., McKenna, B.G., \& Giles, L.C. (2000). Gambling and problem gambling among recently sentenced male prisoners in four New Zealand prisons. Wellington, New Zealand: The Department of Internal Affairs. 
Anderson, D.B. (1999).

Problem gambling among incarcerated male felons. Journal of Offender Rehabilitation, 29 (3-4), 113-127.

Andres, B., \& Hawkeye, S. (1997).

Treating people with gambling problems. In S. Harrison \& V. Carver (Eds.), Alcohol \& drug problems. Toronto: Addiction Research Foundation.

Bellringer, P. (1986).

Gambling and crime: A prison perspective. Society for the Study of Gambling, 8, 9-12.

Blaszczynski, A.P., McConaghy, N., \& Frankova, A. (1991).

Control versus abstinence in the treatment of pathological gambling: A two to nine year follow-up. British Journal of Addiction, 86, 299-306.

Brown, R.I.F. (1987).

Pathological gambling and associated patterns of crime: Comparisons with alcohol and other drug addictions. Journal of Gambling Behavior, 3, 98-114.

Cade, B., \& O'Hanlon, W. (1993).

A brief guide to brief therapy. New York: Norton.

Connolly, D., Williams, R., \& Morris, J. (2001). Impact of statistical knowledge on gambling attitudes and behaviour of university students. Lethbridge, AB: Alberta Gaming Research Institute.

Cox, S., Lesieur, H.R., Rosenthal, R.J., \& Volberg, R.A. (1997).

Problem and pathological gambling in America. Columbia, MD: National Council on Problem Gambling.

Crockford, D.N., \& el-Guebaly, N. (1998).

Psychiatric comorbidity in pathological gambling: A critical review. Canadian Journal of Psychiatry, 43, 43-50.

Ferris, J., \& Wynne, H. (2001).

The Canadian Problem Gambling Index final report. Submitted to the Canadian Centre on Substance Abuse. Ottawa, Ontario: CCSA.

Hazelden Foundation. (2000).

It's not about money. Center City, MN: Author.

Hope, J., \& Havir, L. (2000).

You bet they're having fun! Older Americans and casino gambling. Journal of Aging Studies, 16, 177-197.

Kerber, L. (2000).

Substance use among male inmates. Texas Department of Criminal JusticeInstitutional Division: 1998. Austin, Texas: Texas Commission on Alcohol and Drug Abuse.

Lahn, J., \& Grabosky, P. (2003).

Gambling and clients of ACT Corrections: Final report. Canberra, Australia: Australian 
National University Centre for Gambling Research.

Lesieur, H.R., \& Blume, S.B. (1987).

The South Oaks Gambling Screen (SOGS): A new instrument for the identification of pathological gamblers. American Journal of Psychiatry, 144, 1184-1188.

Lesieur, H.R., \& Blume, S.B. (1993).

Revising the South Oaks Gambling Screen in different settings. Journal of Gambling Studies, 9, 213-223.

Lesieur, H.R., \& Klein, R. (1985, April).

Prisoners, gamblers, and crime. Paper presented at the Academy of Criminal Justice Sciences Annual Meetings, Las Vegas, NV.

Lesieur, H.R., \& Puig, K. (1987).

Insurance problems and pathological gambling. Journal of Gambling Behavior, 3, 123136.

Levinthal, C. (1999).

Drugs, behavior, and modern society (2nd ed.). Boston: Allyn \& Bacon.

Maden, T., Swinton, M., \& Gunn, J. (1992).

Gambling in young offenders. Criminal Behaviour and Mental Health, 2, 300-308.

Meyer, G., \& Stadler, M.A. (1999).

Criminal behavior associated with pathological gambling. Journal of Gambling Studies, 15, 29-43.

Morgan Research (1997).

Report on older people and gambling. Melbourne, Australia: Victorian Casino and Gaming Authority.

Potenza, M.N., Steinberg, M.A., McLaughlin, S.D., Wu, R., Rounsaville, B.J., \& O'Malley, S.S. (2000).

Illegal behaviors in problem gambling: Analysis of data from a gambling helpline. Journal of the American Academy of Psychiatry and the Law, 28, 389-403.

Shaffer, H.J., \& Hall, M.N. (2001).

Updating and refining prevalence estimates of disordered gambling behaviour in the United States and Canada. Canadian Journal of Public Health, 92, 168-172.

Shaffer, H.J., Hall, M.N., \& VanderBilt, J. (1997).

Estimating the prevalence of disordered gambling behavior in the United States and Canada: A research synthesis. American Journal of Public Health, 89, 1369-1376.

Templer, G.I., Kaiser, G., \& Siscoe, K. (1993).

Correlates of pathological gambling propensity in prison inmates. Comprehensive Psychiatry, 34, 347-351.

Toneatto, T., Blitz-Miller, T., Calderwood, K., Dragonetti, R., \& Tasanos, A. (1997). Cognitive distortions in heavy gambling. Journal of Gambling Studies, 13, 253-266.

Volberg, R.A. (2002). 
The epidemiology of pathological gambling. Psychiatric Annals, 32, 171-178.

Walters, G.D. (1997).

Problem gambling in a federal prison population: Results from the South Oaks Gambling Screen. Journal of Gambling Studies, 13, 7-24.

Williams, R.J., Royston, J., \& Hagen, B. (2005).

Gambling and problem gambling within forensic populations: A review of the literature. Criminal Justice and Behavior: An International Journal, 32, 665-689.

Manuscript history: Submitted April 9, 2005, accepted April 10, 2006. This article was peerreviewed.

For correspondence: Gary Nixon, PhD, Associate Professor, School of Health Sciences, University of Lethbridge, 4401 University Drive, Lethbridge, Alberta, Canada T1K 3M4. Phone: (403) 329-2644, fax: (403) 329-2668, e-mail: gary.nixon@uleth.ca

Contributors: GN and GL conceived the study. GN, GL, and NN contributed to the design of the study. GL designed the awareness and prevention program and delivered the program. GL coordinated the pre- and postprogram testing. NN and GN conducted the literature review. NN conducted the statistical analysis of data. GN and GL wrote the initial and final drafts, with GN, GL, and NN all involved in editing.

Competing interests: None declared.

Ethics approval: The University of Lethbridge Human Subjects Research Committee gave Human Subjects Research Approval for the research project "Developing a Gambling Awareness and Prevention Program: Impacting Gambling Behaviour in Prison Populations" on November 6, 2002.

Funding: We gratefully acknowledge direct funding for this project provided by the Alberta Gaming Research Institute. GN is employed as a faculty member with the School of Health Sciences, University of Lethbridge. At the time of this study, NN was employed as a research associate with the School of Health Sciences, University of Lethbridge, and the Alberta Gaming Research Institute. GL is employed as an executive director with the John Howard Society of Lethbridge.

Gary Nixon, PhD, is an associate professor in the School of Health Sciences and Addictions Counselling program coordinator at the University of Lethbridge. Gary is a counselling psychologist with interests in existential, transpersonal, and developmental approaches to counselling and psychotherapy. His research and publications in addictions lie in the areas of seniors, inmates, second-stage recovery, quantum change, ego-transcendence, narrative therapy, and phenomenological-hermeneutics. E-mail: Gary.nixon@uleth.ca

Gordon Leigh, MA, is an executive director with the John Howard Society of Lethbridge. He has developed a number of innovative programs in the addictions field for prison inmates and the community, including the Problem Gambling Awareness and Prevention Program and Life Without Gambling. He is the author of several books and articles about John Howard and the children's book The Law of the Land. E-mail: ljhsbwgl@telusplanet.net 
Nadine Nowatzki, MA, is a doctoral student in the Department of Sociology at the University of Manitoba. Prior to starting her doctorate, she worked as a research associate for the University of Lethbridge, in the School of Health Sciences, and at the Alberta Gaming Research Institute (2001-2004), and at the University of Manitoba, in the Faculty of Medicine (2004-2005). Her current academic interests lie in the sociology of health, specifically social inequality and health. E-mail: nowatzkn@cc.umanitoba.ca

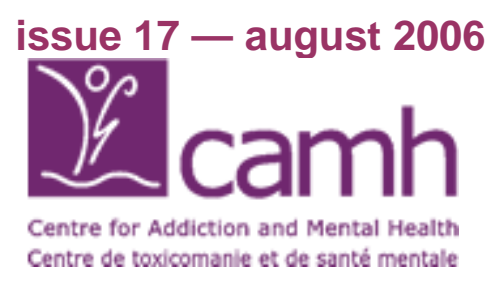

Copyright $\odot$ 1999-2006 The Centre for Addiction and Mental Health

Editorial Contact: phil_lange@camh.net

Subscribe to our automated announcement list: gamble-on@lists.camh.net

Unsubscribe: gamble-off@lists.camh.net 